\title{
Forecasting The Exchange Rate (IDR) of US Dollar (USD) Using Locally Stationary Wavelet
}

\author{
Dina Tri Utari* \\ Program Studi Statistika, FMIPA, Universitas Islam Indonesia, Yogyakarta \\ *dina.t.utari@uii.ac.id
}

\begin{abstract}
Currency exchange rate of a country to the other countries is fluctuated. The movement of the exchange rate affects the country's economy. The exchange rate can change at any time according to the market mechanism, therefore currency exchange predictions are required to determine future economic policy. Based on the impact of the exchange rate on economic fluctuations, an accurate model is needed to determine the exchange rate movements.

In this case study, the Locally Stationary Wavelet (LSW) model was used. This model combines a stochastic process class based on wavelet non-decimated. LSW model can catch most of the information in time series data. Based on the application of LSW method on the data of the rupiah against the US dollar for the period April 2016 March 2017, it can be concluded that model provides forecasting results approaching actual data, therefore, it can be used for forecasting exchange rates. The value of the mean absolute percentage error (MAPE) is $0.1201293 \%$.
\end{abstract}

Keywords: exchange rate, discrete wavelet transforms, $L S W$, forecasting

\begin{abstract}
Abstrak
Nilai tukar mata uang suatu negara terhadap negara lain cenderung fluktuatif. Pergerakan nilai tukar tersebut sangat berpengaruh terhadap perekonomian suatu negara. Nilai tukar dapat berubah setiap saat sesuai mekanisme pasar, oleh karena itu diperlukan prediksi nilai tukar mata uang untuk menentukan kebijakan ekonomi yang akan datang. Mengingat besarnya dampak dari fluktuasi nilai tukar terhadap perekonomian maka dibutuhkan suatu model yang akurat untuk mengetahui pergerakan nilai tukar tersebut.

Pada kasus ini, model yang akan digunakan adalah model Locally Stationary Wavelet (LSW). Model ini menggabungkan kelas proses stokastik berdasarkan wavelet non decimated. Model LSW dapat menangkap sebagian besar informasi dalam data time series. Berdasarkan penerapan model LSW pada data nilai tukar rupiah terhadap dolar Amerika periode April 2016 sampai Maret 2017 diperoleh kesimpulan bahwa metode tersebut menghasilkan nilai peramalan yang mendekati data sebenarnya sehingga dapat digunakan untuk peramalan nilai tukar mata uang. Nilai Mean Absolute Percentage Error (MAPE) yang dihasilkan dari hasil peramalan adalah 0,1201293\%.
\end{abstract}

Kata kunci: nilai tukar, transformasi wavelet diskit, LSW, peramalan 


\section{Pendahuluan}

Kehidupan manusia tak lepas dari suatu proses transaksi jual-beli untuk memenuhi kebutuhan sehari-hari, entah dalam bentuk barang maupun jasa. Untuk melakukan transaksi tersebut, biasanya dibutuhkan suatu alat tukar yang umum diterima, yaitu uang. Uang merupakan sesuatu yang tersedia dan secara umum diterima sebagai alat pembayaran bagi pembelian barang dan jasa. Setiap negara memiliki nilai mata uang sendiri yang digunakan sebagai alat tukar yang sah dalam proses transaksi jual-beli. Dalam proses transaksi jual-beli antarnegara sering kali mengalami sedikit masalah dalam hal pembayaran karena perbedaan nilai uang yang berlaku di setiap negara. Berdasarkan hal ini, maka diperlukanlah suatu mekanisme untuk mengakses nilai tukar mata uang asing. Nilai tukar mata uang (exchange rate/kurs) merupakan suatu perbandingan antara nilai mata uang suatu negara dengan negara lain.

Amerika Serikat (AS) sebagai negara dengan Produk Domestik Bruto (PDB) terbesar, menyebabkan mata uang Amerika Serikat yaitu Dollar AS (USD) mempunyai akses langsung ke pasar barang dan jasa di seluruh dunia. Dengan demikian, USD digunakan sebagai mata uang global untuk melakukan pembayaran internasional yang berlaku di antara negara-negara di dunia. Mata uang memungkinkan mengalami penurunan dan kenaikan setiap saat. Ada beberapa faktor yang mempengaruhi penurunan dan kenaikan mata uang suatu negara, di antaranya yaitu persediaan dan permintaan mata uang asing, posisi balance of payment (BOP), tingkat inflasi, tingkat suku bunga, tingkat pendapatan, pengawasan pemerintah, dan ekspektasi serta spekulasi yang timbul di masyarakat (Hady, 2010). Nilai tukar tidak ditetapkan oleh bank sentral, melainkan pasar, sehingga nilai tukar dapat berubah setiap saat sesuai mekanisme pasar. Oleh karena itu, prediksi nilai tukar mata uang yang akan datang sangat diperlukan untuk menentukan kebijakan ekonomi mendatang.

Berbagai penelitian mengenai peramalan nilai tukar rupiah (IDR) terhadap dollar Amerika Serikat (USD) telah banyak dilakukan. Helmy (2011) menggunakan metode Box-Jenkins (ARIMA) dan Wijayanti, dkk. (2016) menggunakan model fuzzy wavelet untuk meramalkan nilai tukar rupiah terhadap dollar AS. Dalam makalah ini, akan membahas tentang peramalan nilai tukar rupiah (IDR) terhadap dollar AS (USD) menggunakan model Locally 
Stationary Wavelet (LSW). Kelebihan dari model LSW adalah dapat digunakan untuk menganalisis dan meramalkan data time series nonstasioner dan terbukti bermanfaat dalam analisis data keuangan (Fryzlewicz, 2004).

\section{Discrete non-decimated wavelets}

Discrete non-decimated wavelets merupakan dasar untuk mengkonstruksikan proses LSW waktu diskrit. Nason mengkonstruksikan wavelet diskrit $\psi_{j}=\left(\psi_{j, 0}, \ldots, \psi_{j,\left(N_{j}-1\right)}\right) \quad$ dengan panjang $N_{j}$ untuk skala $j<0$ dengan menggunakan formula sebagai berikut:

$\psi_{-1, n}=\sum_{k} g_{n-2 k} \delta_{0, k}=g_{n} \quad$ (pers. 1) untuk $n=0, \ldots, N_{-1}-1$, dan

$\psi_{(j-1), n}=\sum_{k} h_{n-2 k} \psi_{c, k}$ (pers. 2) untuk $\quad n=0, \ldots, N_{-1}-1, \quad N_{j}=$ $\left(2^{-j}-1\right)\left(N_{h}-1\right)+1, \quad$ dengan $\delta_{0, k}$ adalah delta Kronecker dan $N_{h}$ adalah elemen tak nol dari $\left\{h_{k}\right\}$.

Model Locally Stationary Wavelet (LSW)

Proses Locally Stationary Wavelet (LSW) adalah metode yang relatif baru, diperkenalkan oleh Nason (2006). Metode ini menggabungkan kelas proses stokastik berdasarkan nondecimated wavelets. Model LSW dapat menangkap sebagian besar informasi dalam data time series. Fryzlewicz, dkk. (2003) mengembangkan sebuah algoritma untuk meramalkan proses LSW. Prediktor yang digunakan merupakan kombinasi linier dari observasi sebelumnya dengan koefisien prediktor yang diperoleh dengan meminimalkan Mean Square Prediction Error (MSPE). Oleh karena itu peramalan proses non-stasioner dapat dilakukan dengan algoritma ini.

Definisi 1 (Nason (2006)) Sebuah proses LSW adalah barisan ganda dari proses stokastik terindeks $\left\{X_{t, T}\right\}_{t=0, \ldots, T-1}$ yaitu $X_{t, T}=\sum_{j=-J}^{-1} \sum_{k} \omega_{j, k, T} \psi_{j, k-t} \xi_{j, k}$

(pers. 3) dengan $\xi_{j, k}$ adalah barisan kenaikan ortonormal random dan $\psi_{j, k}$ adalah keluarga discrete non-decimated wavelets untuk $j=-1,-2, \ldots,-J(T)$, $k=0, \ldots, T-1$. Asumsi-asumsi yang harus dipenuhi:

1. $E \xi_{j, k}=0$ untuk semua $j, k$. Oleh karena itu, $E X_{t, T}=0$ untuk semua $t$ dan $T$,

2. $\operatorname{cov}\left(\xi_{j, k}, \xi_{l, m}\right)=\delta_{j l} \delta_{k m}$,

3. Amplitudo $\omega_{j, k, T}$ konstan dan untuk setiap $j \leq-1$ terdapat fungsi Lipschitz kontinu $W_{j}(z)$ untuk $z \in(0,1)$ yang memenuhi 
$\sum_{j=-\infty}^{-1} W_{j}^{2}(z)<\infty$ seragam di $z \in(0,1)$ dengan konstanta

Lipschitz $L_{j}$ yang seragam terbatas di $j$ dan $\sum_{j=-\infty}^{-1} 2^{-j} L_{j}<\infty$. Selain itu, terdapat barisan konstanta $C_{j}$ yang memenuhi $\sum_{j} C_{j}<\infty$ sehingga untuk setiap $\sup _{k=0, \ldots, T-1}\left|\omega_{j, k, T}-W_{j}(k / T)\right| \leq$ $C_{j} / T$.

Dengan kata lain proses stokastik stasioner $X_{t}, \quad t \in \mathrm{Z}$ dapat dituliskan sebagai berikut:

$X_{t}=\int_{-\pi}^{\pi} A(\delta) \exp (i \delta t) d \xi(\delta)$ (pers. 4) dengan $d \xi(\delta)$ adalah proses kenaikan ortonormal (Priestley, 1981). Ide dibalik proses LSW adalah untuk menggantikan bentuk harmonik $\{\exp (i \delta t) \mid \delta \in[-\pi, \pi]\} \quad$ pada persamaan (4) ke dalam bentuk discrete non-decimated wavelets $\psi_{j, k}$ dan spektrum $A(\delta)$ berdasarkan waktu yang berbeda-beda $\omega_{j, k, T}$.

Asumsi ketiga memerlukan penghalusan $W_{j}(z)$ sebagai fungsi waktu rescaled, $z$, mengontrol variasi dari $\omega_{j, k}$ sebagai fungsi dari $k$, maka dari itu $W_{j}(z)$ tidak dapat berubah terlalu cepat, sehingga estimasi yang efektif akan diperoleh untuk model. Pada asumsi ini, waktu rescale $z=k / T$ digunakan yang menyiratkan bahwa
$T \rightarrow \infty$, bukan semakin banyak data masa depan, tetapi informasi lokal yang lebih rinci dari $W_{j}(z)$ dapat terkumpul.

Dari definisi proses LSW, perhitungan langsung memberikan struktur kovariansi dengan lag $\tau$ sebagai:

$\operatorname{cov}\left(X_{t, T}, X_{t+\tau, T}\right)=\sum_{j} \sum_{k} \omega_{j, k, T}^{2} \psi_{j, k-t} \psi_{j, k-t-\tau}$

Definisi 2 (Nason (2006)) Evolutionary Wavelet Spectrum (EWS) dari barisan $\left\{X_{t, T}\right\}_{t=0, \ldots, T-1}$ untuk barisan infinit $T \geq 1$ didefinisikan sebagai

$$
S_{j}(z)=W_{j}^{2}(z)
$$

(pers. 5)

untuk $j=-1,-2, \ldots,-J(T), z \in(0,1)$. Dibawah asumsi 3 dari definisi 1 diperoleh $\quad S_{j}(z)=\lim _{T \rightarrow \infty}\left|\omega_{j,[z T], T}\right|^{2}$ dan $\quad \sum_{-\infty}^{-1} S_{j}(z)<\infty \quad$ seragam di $z \in(0,1)$.

EWS mengukur kekuatan lokal (variansi) pada waktu tertentu $Z$ dan skala $j$, yang merupakan analog dari spektrum biasa untuk proses stasioner. Dalam kasus stasioner, EWS adalah independen terhadap waktu, sebagai contoh $S_{j}=\omega_{j, k, T}^{2}=W_{j}^{2}$. Autokovarian didefinisikan sebagai berikut:

$$
c_{T}(z, \tau)=\operatorname{cov}\left(X_{[z T], T}, X_{[z T]+\tau, T}\right)
$$

(pers. 6)

dan autokovarian lokal dengan EWS $S_{j}(z)$ adalah $c(z, \tau)=\sum_{j=-\infty}^{-1} S_{j}(z) \Psi_{j}(\tau), \quad$ dengan 
$\Psi_{j}(\tau)=\sum_{-\infty}^{\infty} \psi_{j, k}, \psi_{j, k-\tau}$ didefinisikan sebagai autokorelasi wavelet. Dari persamaan (6) dapat terlihat bahwa $\left\|c_{T}-c\right\|_{L_{\infty}}=O\left(T^{-1}\right)$ (Nason, 2006), yang menyiratkan bahwa autokovarian lokal adalah transformasi autokorelasi wavelet dari EWS. Secara khusus, varian lokal $\sigma^{2}(z):=c(z, 0)=$ $\sum_{j=-\infty}^{-1} S_{j}(z)$ dengan $\Psi_{j}(0)=1$ untuk semua nilai dari $j$.

\section{Peramalan dengan model LSW}

Fryzlewicz, dkk. (2003) mengembangkan algoritma peramalan untuk proses LSW. Dengan mengamati bahwa proses LSW memiliki bentuk linier, pilihan yang sesuai untuk dipertimbangkan adalah prediktor linier untuk meramalkan $h$ langkah ke depan dari $X_{t-1+h, T}$ diberikan observasi $X_{0, T}, X_{1, T}, \ldots, X_{t-1, T}$ adalah $\widehat{X_{t-1+h, T}}=\sum_{s=0}^{t-1} b_{t-1-s ; T} X_{s, T} \quad$ (pers. 7) Koefisien $b_{j, T}, j=0, \ldots, t-1$ dipilih untuk meminimalkan MSPE yang didefinisikan sebagai $E(\widehat{X-1+h, T}-$ $\left.X_{t-1+h, T}\right)^{2}$. Artinya, vektor $\boldsymbol{b}_{t}=$ $\left(b_{0, T}, \ldots, b_{t-1, T}\right)^{\prime}$ adalah $\boldsymbol{b}_{t}=\arg \min _{b_{t}^{\prime}}\left[\left(\boldsymbol{b}_{t}^{\prime},-1\right) \sum_{t+h-1 ; T}\left(\boldsymbol{b}_{t}^{\prime},-1\right)^{\prime}\right]$ dimana $\sum_{t+h-1 ; T}$ adalah matriks kovarian dari $X_{0, T}, X_{1, T}, \ldots, X_{t-1, T}$ dan $X_{t-1+h, T}$.
Dengan langsung mengambil derivatif bentuk kuadrat dalam persamaan (7), kemudian menyamakannya dengan nol untuk mengarah ke sistem persamaan linier untuk memecahkan $\boldsymbol{b}_{t}$,

$\sum_{t-1 ; T} \boldsymbol{b}_{t}=\boldsymbol{C}_{t-1+h} \triangleq \frac{\boldsymbol{C}_{t-1, h}+\boldsymbol{C}_{h, t-1}^{\prime}}{2}$ (pers. 8)

dengan $\quad \sum_{t-1 ; T}$ adalah matriks kovarian dari $X_{0, T}, X_{1, T}, \ldots, X_{t-1, T}$, $\boldsymbol{C}_{t-1, h}$ adalah vektor kolom dari kovariansi antara $X_{0, T}, X_{1, T}, \ldots, X_{t-1, T}$ dan $X_{t-1+h, T}$ dan $\boldsymbol{C}_{h, t-1}$ adalah vektor kolom dari kovariansi antara $X_{t-1+h, T}$ dan $X_{0, T}, X_{1, T}, \ldots, X_{t-1, T}$. Kovarian ini dapat diestimasi dengan mengestimasi autokovarian lokal.

Dalam prakteknya, ada dua kesepakatan yang harus dibuat sehubungan dengan algoritma di atas. Pertama, $\sum_{t ; T}$ pada persamaan (8) tergantung pada amplitudo $\omega_{j, k ; T}$ yang tidak didefinisikan secara khusus karena redundansi dari keluarga wavelet nondecimated. Berdasarkan pertimbangan teknis, Fryzlewicz, dkk. (2003) memperkirakan $\left(\boldsymbol{b}_{t}^{\prime},-1\right) \sum_{t+h-1 ; T}\left(\boldsymbol{b}_{t}^{\prime},-1\right)^{\prime} \quad$ dengan menggunakan $\left(\boldsymbol{b}_{t}^{\prime},-1\right) \boldsymbol{B}_{t+h-1 ; T}\left(\boldsymbol{b}_{t}^{\prime},-1\right)^{\prime}, \quad$ dengan $\boldsymbol{B}_{t+h-1 ; T}$ adalah matriks berukuran 
$(t+1) \times(t+1)$ dengan elemen ke $(m, n)$ adalah

$\sum_{j=-J}^{-1} S_{j}\left(\frac{n+m}{2 T}\right) \Psi_{j}(n-m)$

(pers. 9)

dan dapat diestimasi dengan mengestimasi EWS $S_{j}$. Kedua, mengingat sifat non-stasioner dan penghalusan lokal dari proses, dianjurkan bahwa hanya $p$ obeservasi terbaru pada persamaan (7) harus digunakan daripada seluruh barisan, yaitu,

$X_{t-1+h, T}^{\widehat{(p)}}=\sum_{S=0}^{t-1} b_{t-1-s ; T} X_{s, T}$.

(pers. 10)

Parameter $p$ serta $g$, bandwidth kernel yang digunakan untuk menghaluskan estimator tidak konsisten dari autokovarian lokal, dapat dipilih secara otomatis berdasarkan peramalan adaptif. Misalkan jika mengamati barisan sampai $X_{t-1, T}$ dan ingin memprediksi $X_{t-1+h, T}$. Pergerakan pertama, katakanlah, $s+h$ langkah mundur dan mulai memprediksi $X_{t-s, T}$ menggunakan $\quad X_{0, T}, X_{1, T}, \ldots, X_{t-h-s, T}$ dengan parameter awal $\left(p_{s}, g_{s}\right)$. Dengan beberapa kriteria yang telah ditentukan (biasanya kriteria jarak minimal atau prediksi absolut relatif eror) dan parameter ruang $(p, g)$, kita memperoleh pasangan optimal $\left(p_{s} *\right.$ ,$g_{s} *$ dan menggunakannya sebagai nilai awal dalam prediksi berikutnya $X_{t-s+1, T}$, dan seterusnya. Setelah proses ini, pasangan $\left(p_{1} *, g_{1} *\right)$ diperbarui yang akhirnya diperoleh untuk peramalan yang sebenarnya. Jumlah $s$ dapat dipilih untuk menjadi panjang segmen terbesar pada akhir barisan yang mengandung ketidakjelasan secara visual pada titiktitik yang teramati. Jika memungkinkan, kita dapat menjalankan algoritma beberapa kali menggunakan $\left(p_{1} *, g_{1} *\right)$ sebagai nilai awal pada iterasi berikutnya sampai diperoleh hasil yang cukup baik.

Hal yang paling penting dalam sebuah peramalah adalah kesalahan atau eror dari peramalan pasti akan selalu ada karena sudah menjadi sifat dasar/alamiah dari sebuah analisis. Namun, diharapkan peramalan yang dilakukan dapat memberikan hasil yang cukup baik, yaitu mendapatkan hasil ramalan yang dapat meminimumkan kesalahan peramalan. Kesalahan peramalan atau forecast error salah satunya bisa diukur dengan Mean Absolute Percentage Error (MAPE). MAPE dihitung dengan persamaan:

$M A P E=\frac{1}{T} \sum_{t=1}^{T}\left|\frac{e_{t}}{X_{t}}\right| \mathrm{x} 100 \% \quad$ (pers. 11) 
dengan $X_{t}$ merupakan data aktual untuk periode ke $t$ dan $e_{t}$ merupakan selisih antara data aktual dan data hasil ramalan pada periode yang sama.

\section{Studi Kasus}

Data yang digunakan dalam studi kasus adalah data nilai tukar rupiah (IDR) terhadap dollar AS (USD) periode 1 April 2016-31 Maret 2017 sebanyak 249 data. Data tersebut merupakan data kurs jual IDR terhadap USD. Data nilai tukar IDR terhadap USD disajikan pada Gambar 1.

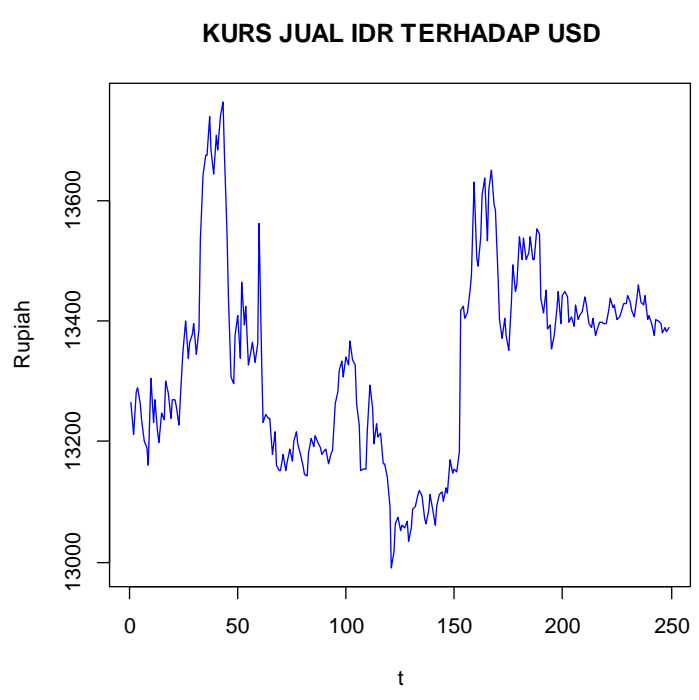

Gambar 1. Kurs Jual IDR terhadap USD

Dari plot pada Gambar 1, diduga bahwa data tidak stasioner karena tidak memiliki nilai rata-rata yang konstan. Nilai rata-rata yang tidak konstan ini adalah sebagai akibat dari adanya efek tren dari data. Selanjutnya, data juga berfluktuasi cukup lebar di sekitar ratarata yang mengindikasikan bahwa data tidak stasioner dalam variansi. Dugaan ini diperkuat dengan uji Augmented Dickey-Fuller dengan hipotesin nol yaitu data tidak stasioner. Nilai $p$-value uji adalah 0,42 yang lebih besar dari 0,05 , hal ini mengindikasikan bahwa tidak cukup alasan menolak $H_{0}$. Dengan kata lain uji ini menyimpulkan bahwa data tidak stasioner.

Selanjutnya dengan menggunakan model LSW, dilakukan pemodelan menggunakan data in sample dan out sample. Data in sample merupakan data yang digunakan untuk pemodelan, sedangkan data out sample merupakan data yang digunakan untuk pengecekan hasil prediksi. Data in sample adalah data dari $t=1$ sampai $t=239$. Kemudian akan diramalkan 10 langkah kedepan yaitu $t=240,241, \ldots, 249$.

Kriteria awal yang harus ditentukan adalah banyaknya waktu peramalan (h) dan nilai $s$ yaitu parameter yang menggambarkan seberapa jauh langkah model harus melangkah ke nilai lampau untuk menghasilkan estiamasi terbaik $p$ dan $g$. Pada data ini diatur $h=10$ dan $s=40$.

Melalui simulasi menggunakan software $R$, didapatkan nilai $p=10$ dan nilai $g=70$. Selanjutnya pemodelan menggunakan persamaan (10) dengan 
$p=10$ dan matriks b diperoleh menggunakan simulasi dengan nilai $g=70$.

Diperoleh hasil peramalan sebagai berikut:

Tabel 1. Perbandingan data aktual dan hasil ramalan

\begin{tabular}{|c|c|c|c|}
\hline$t$ & Aktual & Ramalan & Error \\
\hline 240 & 13409 & 13404,86 & $-4,138250$ \\
\hline 241 & 13396 & 13409,09 & 13,085712 \\
\hline 242 & 13375 & 13409,42 & 34,423438 \\
\hline 243 & 13402 & 13410,34 & 8,338438 \\
\hline 244 & 13399 & 13407,88 & 8,879197 \\
\hline 245 & 13396 & 13406,39 & 10,389174 \\
\hline 246 & 13381 & 13405,52 & 24,522284 \\
\hline 247 & 13390 & 13405,10 & 15,097180 \\
\hline 248 & 13383 & 13406,01 & 23,012180 \\
\hline 249 & 13388 & 13406,93 & 18,927180 \\
\hline \multicolumn{3}{|c|}{ MAPE $=\mathbf{0 , 1 2 0 1 2 9 3 \%}$} \\
\hline
\end{tabular}

Dari Tabel 1 terlihat bahwa hasil ramalan untuk kurs jual IDR terhadap USD cenderung mengalami kenaikan di setiap periode berikutnya. Nilai MAPE hasil peramalan adalah 0,1201293\% atau dapat disimpulkan bahwa diperkiraan kesalahaan perhitungan sebesar 0,1201293\%.

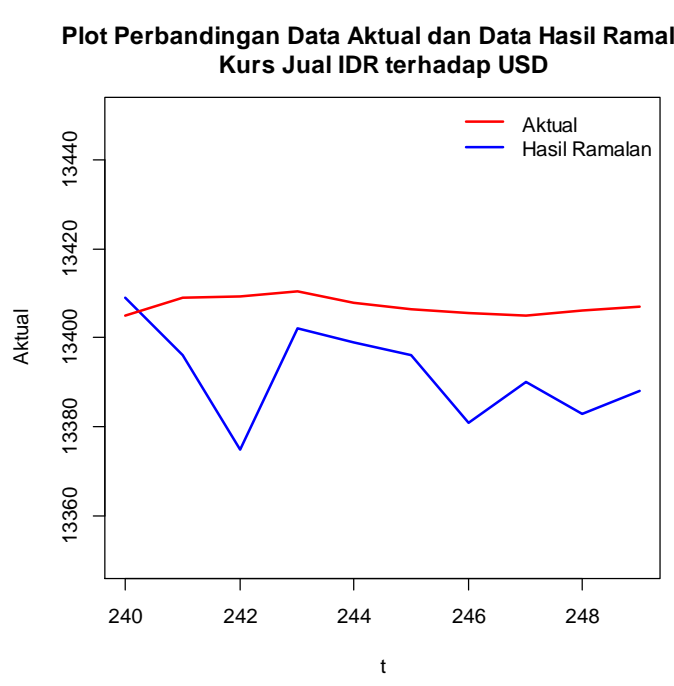

Gambar 2. Perbandingan Data Aktual dan Hasil Ramalan Kurs Jual IDR terhadap USD

Dari Gambar 2 terlihat bahwa pada $t=240$ atau periode 17 Maret 2017 terlihat bahwa data hasil ramalan cukup mendekati data aktualnya. Berdasarkan hasil ramalan yang cenderung mengalami kenaikan dari setiap periode diharapkan jika kurs jual rupiah terhadap dollar meningkat, maka akan mempengaruhi harga pokok penjualan produk dari suatu industri. Hal ini juga akan menyebabkan nilai ekspor mengalami kenaikan, sehingga Indonesia akan memperoleh peningkatan pendapatan nasional.

\section{Kesimpulan}

Kesimpulan yang dapat diperoleh berdasarkan analisis studi kasus yang telah dilakukan adalah sebagai berikut: 
1. Peramalan data time series nonstasioner dapat dilakukan dengan model LSW.

2. Dari studi kasus diperoleh parameter bandwidth kernel yaitu $p=10$ dan $g=70$.

3. Hasil ramalan dari model LSW diperkiraan kesalahaan peramalan nilai tukar rupiah (IDR) terhadap dollar AS (USD) sebesar 0,1201293\%. Dari kurva hasil ramalan diperoleh hasil bahwa hasil ramalan mengalami kenaikan di setiap periode. Diharapkan Indonesia akan memperoleh peningkatan pendapatan nasional dengan adanya kenaikan kurs jual rupiah terhadap dollar AS.

\section{Pustaka}

Fryzlewicz, P., Bellegem, S. V., dan Sachs, R. V. 2003. A waveletbased model for forecasting nonstationary processes. IOP Publishing: Bristol.

Fryzlewicz, P. 2005. Modelling and forecasting financial log-return as locally stationary wavelet processes. Journal of Applied Statistics, 32 (5), pp. 503-528.
Hady, H. 2010. Manajemen Keuangan Internasional. Mitra Wacana Media: Jakarta.

Helmy, H. 2011. Aplikasi Peramalan Kurs Valuta Asing Rupiah per Dollar Amerika Serikat dengan Menggunakan Metode BoxJenkins (ARIMA). TINGKAP Jurnal Ilmiah Ilmu-ilmu Sosial Budaya dan Ekonomi Vol VII No. 1. Universitas Negeri Padang.

Nason, G.P. 2006. Wavelet Methods in Statistics with $R$. Springer. Bristol: University Walk. Odgen, R.T. 1997. Essential Wavelets for Statistical Application and Data Analysis. Birkhauser: Boston.

Priestly, M. B. 1981. Spectral Analysis and Time Series. Academic Press: London.

Wijayanti, T., Abadi, A. M. dan Taufik, M. R. 2016. Application of Wavelet Fuzzy Model to Forecast the Exchange Rate IDR of USD. International Journal of Modeling and Optimization, Vol. 6, No. 1.

Meirianti. 2016. Pengaruh Kemiskinan, Belanja Pemerintah Bidang Pendidikan, Kesehatan dan Ekonomi Terhadap Tingkat IPM di 38 Kabupaten/Kota Provinsi Jawa Timur, 2010-2014. Tugas Akhir. Yogyakarta : Universitas Gadjah Mada. 